\title{
Human brucellosis: recent advances and future challenges
}

\section{David O'Callaghan ${ }^{1,2}$ (D)}

Bacteria of the genus Brucella cause brucellosis, one of the world's neglected zoonotic diseases. It is a disease of poverty; infections of livestock have a huge socioeconomic cost while human brucellosis starts as a debilitating acute infection that can be come chronic with many complications. The figure of 500000 new human cases each year is regularly cited in reviews and research papers, however this is a vast under estimation; many of the most affected countries do not have the infrastructure for diagnosis and the broad spectrum of symptoms are shared with other febrile infections.

Considering the importance of the disease, the international brucellosis research community is small; we cover a wide range of research interests ranging from veterinary and human medicine to molecular genetics, cell biology and immunology. Much work is centred on the deciphering how Brucella cause disease in animals and man; how they enter and survive in host cells, how they use their VirB Type IV secretion system to deliver effectors that modulate host cell biology and immune response.. This will lead to the identification of new strategies for vaccine development, targets for diagnostic and prognostic tests and the development of new therapies. However, as noted in the first few lines of this editorial, brucellosis is a disease of poverty; and it is important that, especially for disease surveillance, diagnosis, control and treatment, that we work for solutions that are relevant and applicable to the countries where the disease is really a problem.

Here I will list a few points that highlight a small selection of the recent practical advances and some of the major challenges.

\footnotetext{
Correspondence: david.o-callaghan@umontpellier.fr

${ }^{1}$ Bacterial Virulence and Infectious Disease, University of Montpellier, INSERM, Nimes, France

${ }^{2}$ Brucellosis National Reference Centre (CNR), Microbiology Laboratory, Caremeau University Hospital, Nimes, France
}

\section{Brucellosis control}

In endemic areas, control of brucellosis is the first challenge. The only way to control human brucellosis is to control the animal disease and stop passage to man. Brucellosis has been controlled or even eradicated in a small number of wealthy countries, by long and costly programs of animal vaccination followed culling of infected animals at later stages. Food hygiene, especially pasteurization of milk is of great importance to prevent human infections. Excellent reviews by JM Blasco [1,2] discus this in detail.

Control of a disease such as brucellosis requires a 'One Health' approach. Animal and human health must work together with the livestock holders and programs established inform and educate the population at risk. Strong implication of political decision makers is essential. If not yet established, surveillance of human and animal populations should be implemented.

Vaccination programs need good vaccines. Two live vaccines, B. melitensis Rev. 1 and B. abortus S19 have been used over past decades with great success for, respectively, small ruminant and bovine brucellosis control programs throughout the world. B. abortus RB51 is also proposed as a vaccine for bovine brucellosis to be used in the final stages of control programs in conjunction with test and slaughter. None of the available vaccines are perfect; they cause abortion in target and non-target animals, can be shed by immunized animals and all can cause brucellosis in humans. RB51 is also resistant to rifampicin, one of the drugs of choice to treat human brucellosis. We need new effective vaccines that are safe for both animals and humans. There are many projects aiming to improve the efficiency and safety of existing vaccines and to develop new vaccines. There is currently an international call for development of a new brucellosis vaccine with a substantial prize for the first new vaccine licensed (https://brucellosisvaccine.org/). Here, the focus

(C) The Author(s). 2020 Open Access This article is licensed under a Creative Commons Attribution 4.0 International License, which permits use, sharing, adaptation, distribution and reproduction in any medium or format, as long as you give appropriate credit to the original author(s) and the source, provide a link to the Creative Commons licence, and indicate if changes were made. The images or other third party material in this article are included in the article's Creative Commons licence, unless indicated otherwise in a credit line to the material. If material is not included in the article's Creative Commons licence and your intended use is not permitted by statutory regulation or exceeds the permitted use, you will need to obtain permission directly from the copyright holder. To view a copy of this licence, visit http://creativecommons.org/licenses/by/4.0/ The Creative Commons Public Domain Dedication waiver (http://creativecommons.org/publicdomain/zero/1.0/) applies to the data made available in this article, unless otherwise stated in a credit line to the data. 
is on a vaccine that will be beneficial in endemic regions. In past years, work has been strongly oriented to vaccines, and diagnostic tools to solve problems in countries with low levels of incidence (generally rich countries in the later stages of control programs). This has led to the DIVA concept (distinguishing between infected and vaccinated animals). While not relevant in a country with high prevalence and no infrastructure to test animals [2], DIVA compliance would make a vaccine more attractive in rich countries and therefore more commercially viable for the manufacturer. The general methods to create a DIVA vaccine have been to remove an immunogenic antigen from the vaccine (such as the loss of O-antigen in RB51). This may reduce efficiency of the vaccine (hence the attempts to restore O-antigen production to RB51 [3]) and mean that accidental human infections are not detected [4]. A more efficient method could be to express an unrelated immunogenic protein in the vaccine strain that would induce a detectable serological response not seen in infected animals. This approach has used for viral vaccines for some time [5] and has recently been used with S19 by the Moreno group in Costa Rica [6].

\section{Strain identification and molecular epidemiology}

MALDI-TOF mass spectrometry is revolutionizing the clinical diagnostic laboratory, but not all machines can identify Brucella. We developed a spectral database allowing Brucella to be identified by the bioMérieux VITEK system [7] and a safe, rapid protocol for solvent inactivation before analysis. Solvent inactivated bacteria are stable for several days, allowing transport to a centre with a machine [8].

Multilocus sequence typing (MLST) and MultipleLocus Variable number tandem repeat Analysis (MLVA) is now used throughout the world for molecular epidemiology. These studies are showing how $B$. melitensis and $B$. abortus strains have been transported across the world by animal trade and will be important in the future control programs $[9,10]$. The advances in sequencing technology will lead to the generalisation and automatization of in silico core genome MLST and MLVA analysis using whole genome sequences.

\section{Scientific Integrity}

The final challenge is not scientific. An increasing number of cases where scientific integrity was not respected. While some may be unintentional, others include data falsification, image manipulation and plagiarism. Scientific advancement is built on the foundations of solid published data. 'Fake Science' is as dangerous as 'Fake News'. It is our responsibility to ensure that all published papers in the field are honest.

I hope that this thematic series of Infectious Diseases of Poverty: Control strategy and case management of human brucellosis, will be the opportunity to report scientific advances in our understanding of brucellosis and describe how they are helping us control this disease.

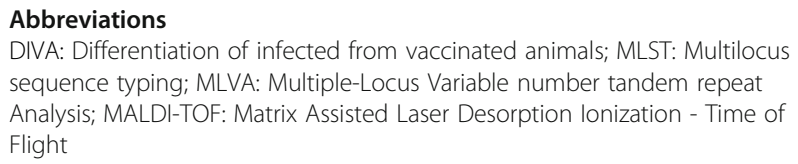

Acknowledgements

Not applicable.

Author's contributions

The author conceived and wrote the manuscript. The author(s) read and approved the final manuscript.

Funding

INSERM, Université de Montpellier, Sante Publique France, ANR, CHU Nimes.

Availability of data and materials

Not applicable.

Ethics approval and consent to participate

Not applicable.

Consent for publication

Not applicable.

Competing interests

Not applicable.

Received: 29 June 2020 Accepted: 3 July 2020

Published online: 23 July 2020

References

1. Basco JM. Control and eradication strategies for Brucella melitensis infection in sheep and goats. Prilozi. 2010;31:145-65.

2. Blasco JM, Molina-Flores B. Control and eradication of Brucella melitensis infection in sheep and goats. Vet Clin North Am Food Anim Pract. 2011;27:95-104.

3. Dabral N, Burcham GN, Jain-Gupta N, Sriranganathan N, Vemulapalli R. Overexpression of wbkF gene in Brucella abortus RB51WboA leads to increased O-polysaccharide expression and enhanced vaccine efficacy against B. abortus 2308, B. melitensis $16 \mathrm{M}$, and B. suis 1330 in a murine brucellosis model. PLoS One. 2019;14:e0213587.

4. Negrón ME, Kharod GA, Bower WA, Walke H. Notes from the field: human Brucella abortus RB51 infections caused by consumption of unpasteurized domestic dairy products - United States, 2017-2019. MMWR Morb Mortal Wkly Rep. 2019;68:185.

5. Walsh EP, Baron MD, Anderson J, Barrett T. Development of a genetically marked recombinant rinderpest vaccine expressing green fluorescent protein. J Gen Virol. 2000;81:709-18..

6. Chacón-Díaz C, Muñoz-Rodríguez M, Barquero-Calvo E, Guzmán-Verri C, Chaves-Olarte E, Grilló MJ, Moreno E. The use of green fluorescent protein as a marker for Brucella vaccines. Vaccine. 2011:29:577-82.

7. Mesureur J, Arend S, Cellière B, Courault P, Cotte-Pattat PJ, Totty H, Deol P, Mick V, Girard V, Touchberry J, Burrowes V, Lavigne JP, O'Callaghan D, Monnin V, Keriel A. A MALDI-TOF MS database with broad genus coverage for specieslevel identification of Brucella. PLoS Negl Trop Dis. 2018;12:e0006874.

8. Mesureur J, Ranaldi S, Monnin V, Girard V, Arend S, Welker M, O'Callaghan D, Lavigne JP, Keriel A. A simple and safe protocol for preparing Brucella samples for matrix-assisted laser desorption ionization-time of flight mass spectrometry analysis. J Clin Microbiol. 2016;54:449-52..

9. Allen AR, Milne G, Drees K, Presho E, Graham J, McAdam P, Jones K, Wright L, Skuce R, Whatmore AM, Graham J, Foster JT. Genomic epizootiology of a Brucella abortus outbreak in Northern Ireland (1997-2012). Infect Genet Evol. 2020;81:104235.

10. Foster JT, Walker FM, Rannals BD, Hussain MH, Drees KP, Tiller RV, Hoffmaster AR, Al-Rawahi A, Keim P, Saqib M. African lineage Brucella melitensis isolates from Omani livestock. Front Microbiol. 2018;8:2702. 